\title{
Alteration of somatosensory response in adulthood by early life stress
}

\author{
Yusuke Takatsuru* and Noriyuki Koibuchi \\ Department of Integrative Physiology, Graduate School of Medicine, Gunma University, Maebashi, Japan
}

Early life stress is well-known as a critical risk factor for mental and cognitive disorders in adulthood. Such disorders are accompanied by altered neuro- (synapto-) genesis and gene expression. Because psychosomatic disorders induced by early life stress (e.g., physical and/or sexual abuse, and neglect) have become a socio-economic problem, it is very important to clarify the mechanisms underlying these changes. However, despite of intensive clinical and animal studies, such mechanisms have not yet been clarified. Although the disturbance of glucocorticoid and glutamate homeostasis by stress has been well-documented, it has not yet been clarified whether such disturbance by early life stress persists for life. Furthermore, since previous studies have focused on the detection of changes in specific brain regions, such as the hippocampus and prefrontal cortex, it has not been clarified whether early life stress induced changes in the sensory/motor system. Thus, in this review, we introduce recent studies on

OPEN ACCESS

Edited by:

Xiao-Dong Wang,

Zhejiang University, China

Reviewed by:

Fabrizio Gardoni,

University of Milan, Italy Boldizsar Czeh,

University of Pécs, Hungary

*Correspondence: Yusuke Takatsuru, Department of Integrative Physiology, Graduate School of Medicine, Gunma University, Maebashi, Gunma 371-8511, Japan takatsur@gunma-u.ac.jp

Received: 09 March 2015 Accepted: 05 May 2015 Published: 19 May 2015

Citation:

Takatsuru Y and Koibuchi N (2015) Alteration of somatosensory response in adulthood by early life stress.

Front. Mol. Neurosci. 8:15. doi: 10.3389/fnmol.2015.00015 functional/structural changes in the somatosensory cortex induced by early life stress. We believe that this review provides new insights into the functional alteration of the somatosensory system induced by early life stress. Such information may have clinical relevance in terms of providing effective therapeutic interventions to early life stressed individuals.

Keywords: maternal deprivation, in vivo imaging, in vivo microdialysis, glutamate reseptor, spine

\section{Introduction}

Early life stress during the perinatal period induces functional and anatomical changes in the brain. Unfortunately, some of such changes persist in adulthood. Clinical studies have shown that early life stress during childhood persistently impairs cognitive and emotional functions, sometimes until adulthood (Chugani et al., 2001; Nelson et al., 2007; Gatt et al., 2009; Mueller et al., 2010; Gershon et al., 2013; Pesonen et al., 2013). Stress-induced alterations of neuronal activity and stress-related hormone secretion may affect neurological development such as dendrite arborization, synaptogenesis, and spine formation (McEwen, 1999; Vyas et al., 2002; Liston et al., 2006). These perinatal stress-induced morphological changes may alter the brain function throughout life (Romeo and McEwen, 2006; Shair, 2007; Gershon et al., 2013). However, it has not yet been clarified how the type, intensity and duration of stress affect different brain regions with different persistence (Romeo and McEwen, 2006). For example, although it has been well-known since several decades ago that acute stress disturbs glutamate and/or corticosterone homeostasis (Moghaddam, 1993; Moghaddam et al., 1994), it has not yet 
been clarified whether such a glutamate/corticosterone disturbance persists for a long time in a region- and temporalspecific manner after early life stress exposure (Popoli et al., 2011).

To study the effect of early life stress, various animal models have been introduced with their potential applications in humans (Shair, 2007). In these models, early life stress induces various disorders in adulthood, e.g., an enhancement of anxiety-related behaviors (Wigger and Neumann, 1999; Parfitt et al., 2004; Slotten et al., 2006; Shair, 2007). Such behavioral alteration is partly induced by structural changes of hippocampal neurons and changes in the rate of release of several neurotransmitters/hormones in this region (Brunson et al., 2005; Aisa et al., 2007; Oomen et al., 2010). The electrophysiological changes are also detected in the hippocampus of aged animals (Sousa et al., 2014). Early life stressed rodents also show neuronal changes such as those in synaptic spine density in the infralimbic cortex (Ovtscharoff and Braun, 2001). Early life stress also affects the expression levels of $\alpha$-amino-3-hydroxy-5-methylisoxazole4-propionic acid (AMPA) receptor by suppressing the function of $\mathrm{Ca}^{2+}$ calcium/calmodulin-dependent protein kinase type II (CaMKII) in the barrel cortex (Miyazaki et al., 2012). These findings indicate that early life stress during the perinatal period affects the brain function/structure in various brain regions. However, most studies have been performed focusing in several specific brain regions such as the hippocampus and prefrontal cortex (Wigger and Neumann, 1999; Parfitt et al., 2004; Slotten et al., 2006; Shair, 2007; Miyazaki et al., 2012). Thus, it has not yet been clarified whether early life stress disrupts the somatosensory function.

In this review, we discuss the effect of early life stress on somatosensory function by introducing our recent studies. Most of the results were obtained by in vivo studies such as in vivo imaging using two- (multi-) photon laser microscopy and freemoving in vivo microdialysis. This review may provide novel insights into the functional alterations of the somatosensory system induced by early life stress. Such information may be useful in terms of providing effective therapeutic interventions to early life stressed individuals.

\section{Persistent Alteration of Synaptic Turnover in the Somatosensory Cortex in Early Life Stressed Mice}

Effects of early life stress can be seen in various brain regions. Such effects are observed as changes in synaptic spine density, synaptic turnover rate, electrophysiological properties, neurotransmitters release or expression levels of neuronal and glial proteins. However, it is difficult to identify specific regions affected by a specific early life stress. Even if a particular neuropsychological phenotype is observed, it may still be difficult to identify the affected brain regions, because of the complexity of the mechanisms underlying these changes. In the hippocampus, for example, early life stress alters the spine density and dendritic outgrowth of pyramidal neurons (Magarinos and McEwen, 1995; Pawlak et al., 2005; Monroy et al., 2010; Magarinos et al., 2011), with the change in the expression levels of proteins such as neurotrophic factors and transcription factors (Lippmann et al., 2007; Nair et al., 2007; Kawano et al., 2008; Magarinos et al., 2011; Horii-Hayashi et al., 2013; Suri et al., 2013; Dimatelis et al., 2014). Such an alteration may lead to impaired memory acquisition and cognitive function (Huot et al., 2002; Aisa et al., 2007; Fabricius et al., 2008; Suri et al., 2013; Connors et al., 2015). However, involvement of other brain region cannot be excluded. On the other hand, the somatosensory cortex receives sensory information such as pain, temperature, and pressure, integrates them to identify the object (Haggard, 2006). Its disorder produces difficulties in interpreting tactile information (Freund, 2003; Tinazzi et al., 2013). However, the effect of early life stress on somatosensory function has not yet been clarified. In the somatosensory cortex, the spine density is rather stable after early life stress compared with those in the hippocampus not only in juveniles but also in adults (Takatsuru et al., 2009a). Nevertheless, the nociceptive threshold is significantly decreased in early life stressed juvenile (4 weeks-old) and adult mice (12 weeksold; Takatsuru et al., 2009a). Electrophysiologically, the slope $(\mu \mathrm{V} / \mathrm{ms})$ of field potential in layer II/III evoked by vibrotactile somatosensory simulation increases in early life stressed adult mice. Interestingly, these changes significantly correlate with the decrease in nociceptive threshold (Figure 1; Toya et al., 2014), indicating that somatosensory function is persistently altered by early life stress.

As discussed above, although the somatosensory response is altered by the change in electrophysiological properties, previous studies have shown slight morphological changes in the somatosensory cortex (Takatsuru et al., 2009a). To clarify further the mechanism inducing neurological alterations, it is necessary to apply additional techniques such as twophoton laser microscopy (Denk et al., 1990; Grutzendler et al., 2002; Trachtenberg et al., 2002). This technique enables us to examine dynamic changes in synaptic turnover rate and neuronal excitability during neuronal circuit remodeling (Takatsuru et al., 2009b).

In early life stressed mice, the turnover rate of mushroom spines, which usually maintain their structure for a long time (Grutzendler et al., 2002; Trachtenberg et al., 2002), is significantly increased in the somatosensory cortex in not only juvenile but also in adult mice (Takatsuru et al., 2009a). Because both of the gain and loss of spines occur simultaneously, the total number of spines is not markedly altered. However, two-photon microscopy enabled us to detect the persistent dynamic changes in synaptic turnover induced by early life stress. These findings indicate that early life stress destabilizes synaptic formation in the somatosensory cortex, resulting in the disturbance of somatosensory function.

Although we have shown the persistent increase in synaptic turnover rate in the somatosensory cortex induced by early life stress, the mechanisms underlying such an alteration have not yet been clarified. One possibility is the involvement of microglia. Recently, we have found the alteration of motility of microglia in early life stressed mice in vivo (Takatsuru et al., 2015). The motility of the filopodia-like processes is increased in early life stressed mice. Interestingly, the motility of the 

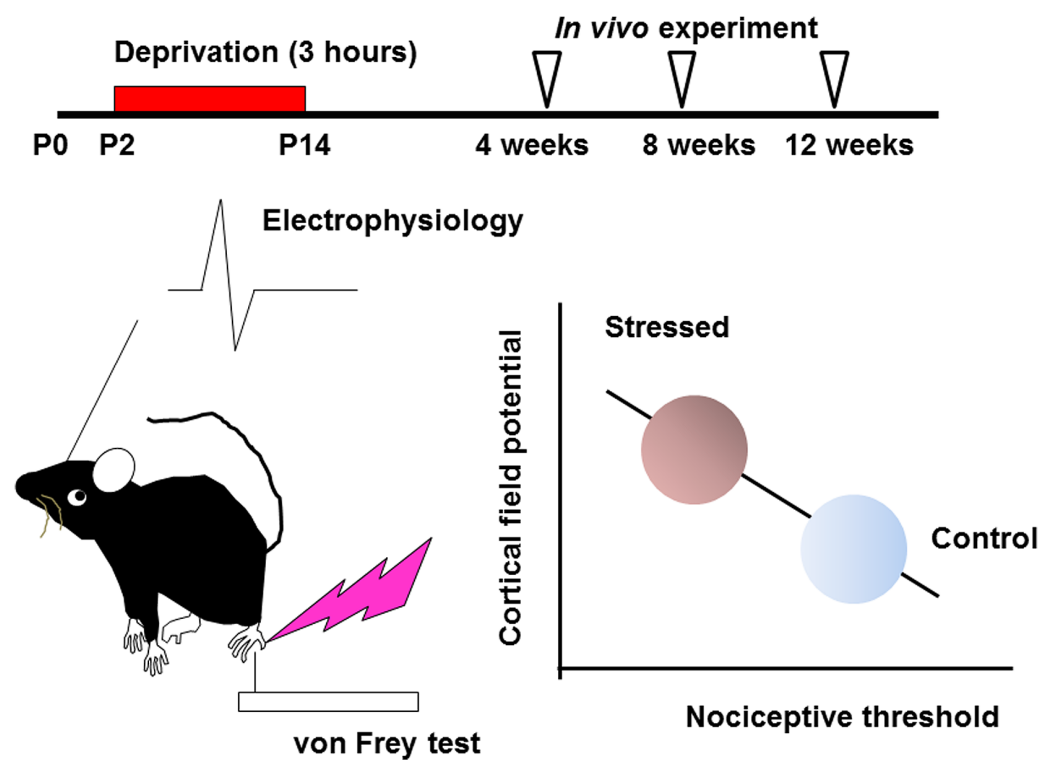

FIGURE 1 | Early life stress induces hyperactivity of somatosensory function (see Takatsuru et al., 2009a and Toya et al., 2014, for details). Maternal deprivation is performed from postnatal day P2 to $\mathrm{P} 14,3 \mathrm{~h}$ per day (the day of birth is determined as P0). After weaning, an in vivo experiment is performed from 4 to 12 weeks. In early life stressed mice, the nociceptive threshold studied by von Frey hair test decreases with increasing cortical field potential. These values significantly correlate. processes negatively correlates with the somatosensory threshold (the motility is higher in the mice with a lower threshold). Furthermore, the number of processes is significantly increased in early life stressed mice after acute somatosensory stimulation and such an increase persists for several hours. The motility of microglia is changed by neuronal conditions as in the case of remodeling of synapses after a focal stroke (Wake et al., 2013). Because previous studies indicate that microglia may partly regulate synaptic formation by removing or 'stripping' synapses (Marín-Teva et al., 2004; Cullheim and Thams, 2007; Tremblay, 2011) and because the direct contact of microglial processes with spines has been observed (Wake et al., 2013), the activity of microglia increased by early life stress may contribute to the structural instability of spines in the somatosensory cortex. In a series of study, we have clarified that not only severe brain damage such as ischemia or inflammation, but also psychological stress such as maternal separation can produce persistent changes in microglial activity. However, early life stress factors activating microglia have not yet been clarified. In the next section, we will discuss several possible factors for such activation.

\section{Persistent Alterations of Glutamate and Glucocorticoid Homeostasis in the Somatosensory Cortex Induced by Early Life Stress}

Early life stress may induce alterations of neurotransmitters (Barbosa Neto et al., 2012; Martisova et al., 2012; Gunn et al., 2013) and neurotrophic factors in various brain regions (Lippmann et al., 2007; Nair et al., 2007; Kawano et al., 2008;
Magarinos et al., 2011; Horii-Hayashi et al., 2013; Suri et al., 2013; Dimatelis et al., 2014). Such alteration may produce changes in the structure of neural circuits, spine turnover rate, and/or microglial motility. Since many critical developmental events occur in the neonatal period, even weak environmental insults may produce irreversible alterations in organ homeostasis. Indeed, disruption of homeostasis of glucocorticoid release by administering excess amounts of corticosterone produces various abnormalities such as those in the number of spines, synaptic turnover rate, microglial motility, electrophysiological properties, and astrocyte function (Gunn et al., 2013). However, it has not yet been clarified whether such alterations occur in the somatosensory cortex. Detecting the concentration of a neurotransmitter such as glutamate or GABA in the cortex may reveal the mechanisms underlying the change in the turnover rate of mushroom spines. In vivo microdialysis is a potent technique to observe the neuronal transmitter release under intact condition although the spatial resolution is limited. This technique also enables local drug application, which is usually difficult due to the blood-brain barrier (Takatsuru et al., 2013). Using this technique, we have found that the concentration of glutamate is increased in early life stressed mice under freemoving condition (Figure 2; Toya et al., 2013, 2014). We have also reported that the homeostasis of coritcosterone is also affected by early life stress (Toya et al., 2014).

Corticosterone may play a protective role in neuronal circuits against stress (McEwen, 2000a,b). Glucocorticoids convert proteins and/or lipids into carbohydrates, which can be easily used for energy production. This conversion will serve the body well in the short run by replenishing energy reserves after a period of activity, as in a situation such as running away from 


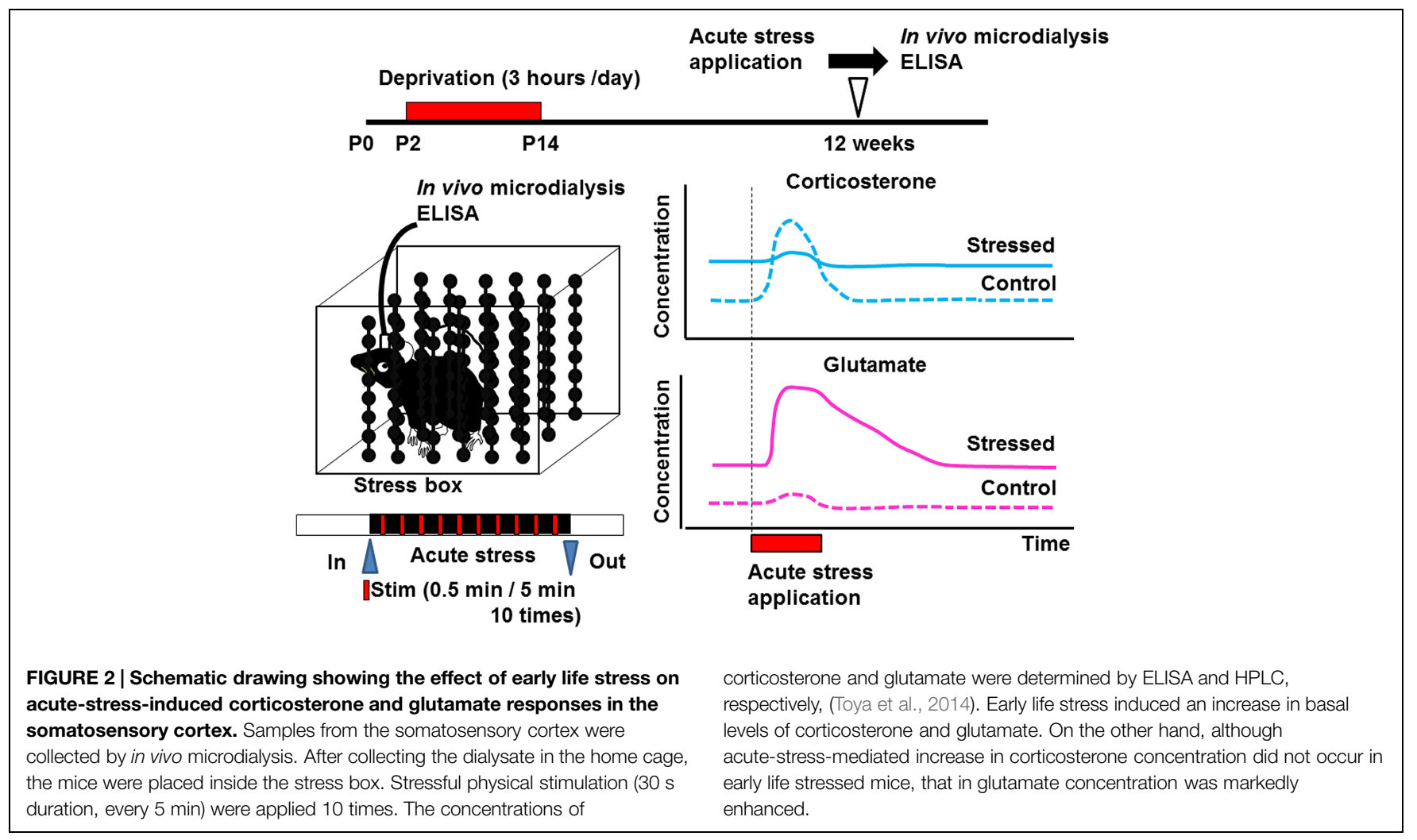

a predator (McEwen, 2000b). Glucocorticoids also increase the appetite for food and promote food-seeking behavior (Leibowitz and Hoebel, 1997). Thus, enhancement of corticosterone release under acute stress potentially protects the body from stress. However, a long-term increase in corticosterone concentration induces dendritic atrophy in some brain regions (McEwen,

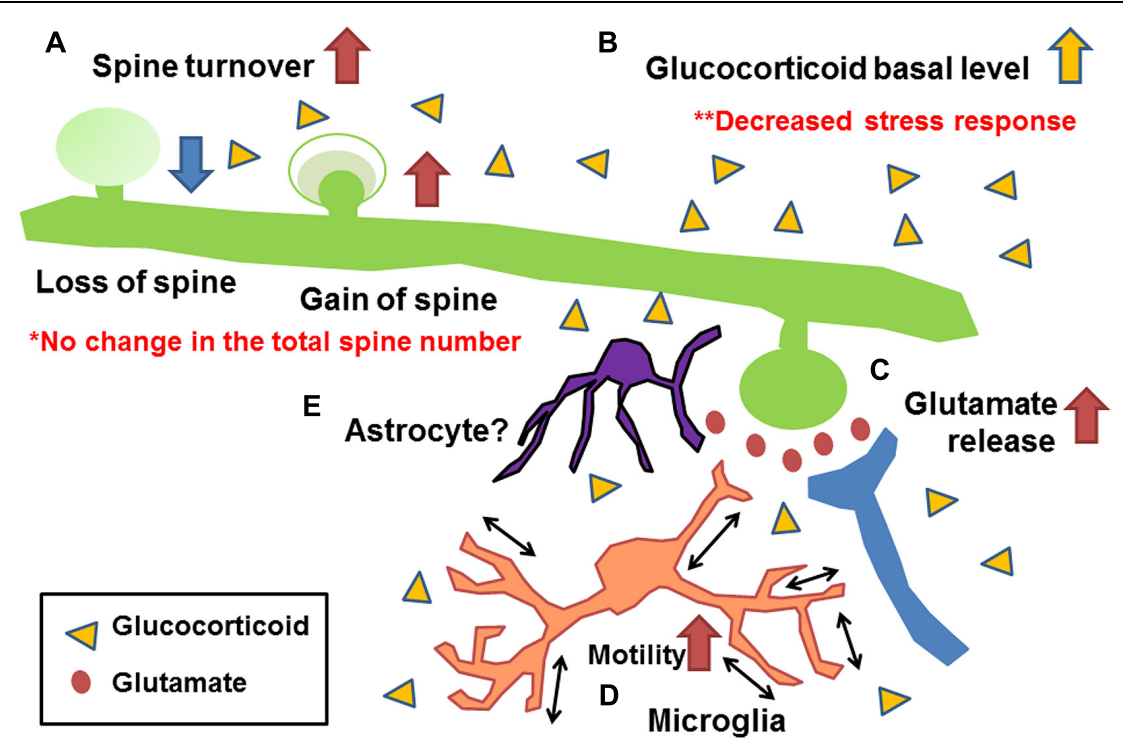

FIGURE 3 | Schematic drawing showing the morphological/chemical alterations induced by early life stress in the somatosensory cortex (Takatsuru et al., 2009a, 2015; Toya et al., 2014). (A) Increase in mushroom spine turnover rate without significant alteration of total number of spines, (B) increase in basal glutamate level and acute-stress-mediated increase in glutamate level, (C) increase in basal level of corticosterone without further increase under acute stress, and (D) increase in microglial motility. Although the involvement of astrocytes has not yet been clarified (E), studies of other brain regions indicate their possible involvement (Gunn et al., 2013). 
2000a) and thus, the concentration of corticosterone should be carefully controlled to maintain the homeostasis of body/brain functions. Furthermore, perinatal stress sometimes disrupts hypothalamic-pituitary-adrenal axis, resulting into persistent aberrant glucocorticoid secretion (Faturi et al., 2010; Koe et al., 2014; Nishi et al., 2014). Under such conditions, the protective role of glucocorticoids in neural circuits may be disrupted. Thus, an increased basal corticosterone concentration in the somatosensory cortex in early life stressed animals may be partly involved in inducing spine instability, glutamate secretion, and microglia motility. Disruption of glucocorticoid responses to acute stress may exacerbate such instability.

In early life stressed animals, the basal concentration of glutamate in the somatosensory cortex increases markedly (Toya et al., 2014). It has been well-known that the acute stress disrupts glutamate homeostasis (Moghaddam, 1993). However, it has not yet been clarified whether such disruption persists for life after early life stress in a specific brain region. Our study clearly demonstrated the increase in glutamate level in adulthood by early life stress in the somatosensory cortex. On the other hand, in control mice, the concentration of glutamate is rather stable after acute-stress application (Toya et al., 2014). This is probably due to the activation of glial cells that take up excess glutamate, thus preventing excitotoxity (Danbolt, 2001; Takayasu et al., 2009). In early life stressed mice, on the other hand, although the basal glutamate concentration is sixfold that in control mice, acute stress further increased the concentration of glutamate. Such a further increase lasts longer than $1 \mathrm{~h}$ after stimulation. These findings indicate the alteration of glutamate homeostasis by early life stress. However, the interaction between enhanced glutamate release and suppressed corticosterone response induced by acute stress early in life of mice has not yet been clarified.

Although the mechanisms inducing the persistently enhanced glutamate release in the somatosensory cortex induced by early life stress have not yet been fully understood, previous studies have provided several clues. Environmental stress enhances glutamate release and suppresses glial-cell-mediated glutamate cycling. Such changes affect synaptic transmission in the limbic/cortical areas (Sanacora et al., 2012). Early life stress also affects the structural organization, i.e., dendritic remodeling, reduction of synaptic spine formation, glial cell loss, and possibly volumetric reductions of several specific brain regions of the rodent brain (Sanacora et al., 2012). Acute exposure to stress or administration of glucocorticoids rapidly promotes glutamate release in the hippocampus and other brain regions (Lowy et al., 1993; Moghaddam, 1993; Reznikov et al., 2007). The glucocorticoid-receptor-mediated increase in the expression levels of presynaptic soluble $N$-ethylmaleimidesensitive factor attachment protein receptor (SNARE) protein complexes are induced in the presynaptic membrane in the prefrontal/frontal cortex by acute stress. SNARE then enhances the release of glutamate (Musazzi et al., 2010). The Rab4mediated recycling of NMDA and AMPA receptors from early endosomes is also enhanced in the prefrontal cortex (Yuen et al., 2009). Chronic stress also decreases the number of glial fibrillary acid protein (GFAP)-expressing cells and the impaired clearance of synaptic glutamate through excitatory amino acid transporters in the prefrontal cortex (Banasr and Duman, 2008). Taken together, it is reasonable to speculate that early life stress may alter glucocorticoid homeostasis, and such an alteration may enhance glutamate release by stimulating the expression of proteins related to glutamate release and sensitivity. The activity of glial cells, which take up glutamate, may also be affected, inducing an increase in interstitial glutamate level.

On the basis of the findings mentioned above, we examined the involvement of glutamate receptor subunits of AMPA, NMDA, and metabotropic glutamate receptors after application of acute stress in early life stressed mice to clarify the underling mechanisms by Western blot analysis (Toya et al., 2013). However, protein levels of these subunits in the membrane fraction were not significantly different between the control and early life stressed animals before and after acute-stress application. Because we carried out only Western blot analysis, further study to determine the protein turnover rate by in vivo imaging may be required. Under the present condition, however, we were unable to detect the involvement of glutamate receptors in the alteration of somatosensory function induced by early life stress.

\section{Summary and Perspectives}

Figure 3 shows a summary of the effects of early life stress in the somatosensory cortex. We found the following; (A) Increase in mushroom spine turnover rate without significant alteration of the total number of spines, (B) Increase in basal level of corticosterone without further increase under acute stress, (C) Increase in basal and acute-stress-mediated glutamate levels, and (D) Increase in microglial motility. A combination of these alterations may have affected somatosensory function. Unfortunately, however, we failed to identify molecules involved in such alterations. One possible reason for the failure is that, although we detected a significant increase in synaptic turnover rate and microglial motility with a decreased somatosensory threshold and an increased electrophysiological activity, less than $10 \%$ of all spines were lost or gained. Thus, only a limited amount of molecules may be involved in such subtle changes. To detect such changes, Western blot analysis may not be a suitable technique. More sophisticated techniques such as detection of protein trafficking and/or protein expression at the single-cell level may be required. Nevertheless, our series of studies have demonstrated the persistent alteration of somatosensory function induced by early life stress with morphological/chemical alterations in the somatosensory cortex. Although the involvement of astrocytes has not yet been clarified, a previous study has shown that early life stress decreases glutamate uptake in the hypothalamus (Gunn et al., 2013). Thus, such a decrease may also be induced in the somatosensory cortex (Figure 3E). Trials to clarify the involvement of astrocytes are currently underway. However, as discussed above, the morphological/chemical changes in the somatosensory cortex are not always identical to those in other brain regions. Thus, more 
careful analysis may be required to examine the brain regionspecific effects of early life stress. In particularly, more attention should be paid to the change in somatosensory function in early life stressed humans, because only limited information is

\section{References}

Aisa, B., Tordera, R., Lasheras, B., Del Río, J., and Ramírez, M. J. (2007). Cognitive impairment associated to HPA axis hyperactivity after maternal separation in rats. Psychoneuroendocrinology 32, 256-266. doi: 10.1016/j.psyneuen.2006.12.013

Banasr, M., and Duman, R. S. (2008). Glial loss in the prefrontal cortex is sufficient to induce depressive-like behaviors. Biol. Psychiatry 64, 863-870. doi: 10.1016/j.biopsych.2008.06.008

Barbosa Neto, J. B., Tiba, P. A., Faturi, C. B., de Castro-Neto, E. F., da Graça NaffahMazacoratti, M., de Jesus Mari, J., et al. (2012). Stress during development alters anxiety-like behavior and hippocampal neurotransmission in male and female rats. Neuropharmacology 62, 518-526. doi: 10.1016/j.neuropharm.2011.09.011

Brunson, K. L., Kramár, E., Lin, B., Chen, Y., Colgin, L. L., Yanagihara, T. K., et al. (2005). Mechanisms of late-onset cognitive decline after early-life stress. J. Neurosci. 25, 9328-9338. doi: 10.1523/JNEUROSCI.2281-05.2005

Chugani, H. T., Behen, M. E., Muzik, O., Juhasz, C., Nagy, F., and Chugani, D. C. (2001). Local brain functional activity following early deprivation: a study of postinstitutionalized Romanian orphans. Neuroimage 14, 1290-1301. doi: 10.1006/nimg.2001.0917

Connors, E. J., Migliore, M. M., Pillsbury, S. L., Shaik, A. N., and Kentner, A. C. (2015). Environmental enrichment models a naturalistic form of maternal separation and shapes the anxiety response patterns of offspring. Psychoneuroendocrinology 52, 153-167. doi: 10.1016/j.psyneuen.2014.10.021

Cullheim, S., and Thams, S. (2007). The microglial networks of the brain and their role in neuronal network plasticity after lesion. Brain Res. Rev. 55, 89-96. doi: 10.1016/j.brainresrev.2007.03.012

Danbolt, N. C. (2001). Glutamate uptake. Prog. Neurobiol. 65, 1-105. doi: 10.1016/S0301-0082(00)00067-8

Denk, W., Strickler, J. H., and Webb, W. W. (1990). Two-photon laser scanning fluorescence microscopy. Science 248, 73-76. doi: 10.1126/science.2321027

Dimatelis, J. J., Russell, V. A., Stein, D. J., and Daniels, W. M. (2014). Methamphetamine reversed maternal separation-induced decrease in nerve growth factor in the ventral hippocampus. Metab. Brain Dis. 29, 433-439. doi: 10.1007/s11011-014-9481-z

Fabricius, K., Wörtwein, G., and Pakkenberg, B. (2008). The impact of maternal separation on adult mouse behaviour and on the total neuron number in the mouse hippocampus. Brain Struct. Funct. 212, 403-416. doi: 10.1007/s00429007-0169-6

Faturi, C. B., Tiba, P. A., Kawakami, S. E., Catallani, B., Kerstens, M., and Suchecki, D. (2010). Disruptions of the mother-infant relationship and stressrelated behaviours: altered corticosterone secretion does not explain everything. Neurosci. Biobehav. Rev. 34, 821-834. doi: 10.1016/j.neubiorev.2009.09.002

Freund, H. J. (2003). Somatosensory and motor disturbances in patients with parietal lobe lesions. Adv. Neurol. 93, 179-193.

Gatt, J. M., Nemeroff, C. B., Dobson-Stone, C., Paul, R. H., Bryant, R. A., Schofield, P. R., et al. (2009). Interactions between BDNF Val66Met polymorphism and early life stress predict brain and arousal pathways to syndromal depression and anxiety. Mol. Psychiatry 14, 681-695. doi: 10.1038/mp.2008.143

Gershon, A., Sudheimer, K., Tirouvanziam, R., Williams, L. M., and O'Hara, R. (2013). The long-term impact of early adversity on late-life psychiatric disorders. Curr. Psychiatry Rep. 15:352. doi: 10.1007/s11920-0130352-9

Grutzendler, J., Kasthuri, N., and Gan, W. B. (2002). Long-term dendritic spine stability in the adult cortex. Nature 420, 812-816. doi: $10.1038 /$ nature 01276

Gunn, B. G., Cunningham, L., Cooper, M. A., Corteen, N. L., Seifi, M., Swinny, J. D., et al. (2013). Dysfunctional astrocytic and synaptic regulation of hypothalamic glutamatergic transmission in a mouse model of earlylife adversity: relevance to neurosteroids and programming of the stress response. J. Neurosci. 33, 19534-19554. doi: 10.1523/JNEUROSCI.133713.2013 available at present. We believe that this review has provided an important clue to developing effective therapeutic interventions to prevent persistent somatosensory abnormalities induced by early life stress.

Haggard, P. (2006). Sensory neuroscience: from skin to object in the somatosensory cortex. Curr. Biol. 16, R884-R886. doi: 10.1016/j.cub.2006.09.024

Horii-Hayashi, N., Sasagawa, T., Matsunaga, W., Matsusue, Y., Azuma, C., and Nishi, M. (2013). Developmental changes in desensitisation of c-Fos expression induced by repeated maternal separation in pre-weaned mice. J. Neuroendocrinol. 25, 158-167. doi: 10.1111/j.1365-2826.2012.02377.x

Huot, R. L., Plotsky, P. M., Lenox, R. H., and McNamara, R. K. (2002). Neonatal maternal separation reduces hippocampal mossy fiber density in adult Long Evans rats. Brain Res. 950, 52-63. doi: 10.1016/S0006-8993(02)02985-2

Kawano, K., Morinobu, S., Sawada, T., Tsuji, S., Erabi, K., Fuchikami, M., et al. (2008). Prior neonatal isolation reduces induction of NGF mRNA and decreases GDNF mRNA in the hippocampus of juvenile and adult rodents subjected to immobilization stress. Synapse 62, 259-267. doi: 10.1002/syn.20487

Koe, A. S., Salzberg, M. R., Morris, M. J., O’Brien, T. J., and Jones, N. C. (2014). Early life maternal separation stress augmentation of limbic epileptogenesis: the role of corticosterone and HPA axis programming. Psychoneuroendocrinology 42, 124-133. doi: 10.1016/j.psyneuen.2014.01.009

Leibowitz, S. F., and Hoebel, B. G. (1997). "Behavioral neuroscience of obesity," in Handbook of Obesity, Chap. 15, eds G. A. Bray, C. Bouchard, and W. P. T. James (New York, NY: Marcel Dekker), 313-358.

Lippmann, M., Bress, A., Nemeroff, C. B., Plotsky, P. M., and Monteggia, L. M. (2007). Long-term behavioural and molecular alterations associated with maternal separation in rats. Eur. J. Neurosci. 25, 3091-3098. doi: 10.1111/j.14609568.2007.05522.x

Liston, C., Miller, M. M., Goldwater, D. S., Radley, J. J., Rocher, A. B., Hof, P. R., et al. (2006). Stress-induced alterations in prefrontal cortical dendritic morphology predict selective impairments in perceptual attentional setshifting. J. Neurosci. 26, 7870-7874. doi: 10.1523/JNEUROSCI.1184-06.2006

Lowy, M. T., Gault, L., and Yamamoto, B. K. (1993). Adrenalectomy attenuates stress-induced elevations in extracellular glutamate concentrations in the hippocampus. J. Neurochem. 61, 1957-1960. doi: 10.1111/j.14714159.1993.tb09839.x

Magarinos, A. M., Li, C. J., Gal Toth, J., Bath, K. G., Jing, D., Lee, F. S., et al. (2011). Effect of brain-derived neurotrophic factor haploinsufficiency on stressinduced remodeling of hippocampal neurons. Hippocampus 21, 253-264. doi: 10.1002/hipo. 20744

Magarinos, A. M., and McEwen, B. S. (1995). Stress-induced atrophy of apical dendrites of hippocampal CA3c neurons: involvement of glucocorticoid secretion and excitatory amino acid receptors. Neuroscience 69, 89-98. doi: 10.1016/0306-4522(95)00259-L

Marín-Teva, J. L., Dusart, I., Colin, C., Gervais, A., van Rooijen, N., and Mallat, M. (2004). Microglia promote the death of developing Purkinje cells. Neuron 41, 535-547. doi: 10.1016/S0896-6273(04)00069-8

Martisova, E., Solas, M., Horrillo, I., Ortega, J. E., Meana, J. J., Tordera, R. M., et al. (2012). Long lasting effects of early-life stress on glutamatergic/GABAergic circuitry in the rat hippocampus. Neuropharmacology 62, 1944-1953. doi: 10.1016/j.neuropharm.2011.12.019

McEwen, B. S. (1999). Stress and hippocampal plasticity. Annu. Rev. Neurosci. 22, 105-122. doi: 10.1146/annurev.neuro.22.1.105

McEwen, B. S. (2000a). The neurobiology of stress: from serendipity to clinical relevance. Brain Res. 886, 172-189. doi: 10.1016/S0006-8993(00)02950-4

McEwen, B. S. (2000b). Allostasis and allostatic load: implications for neuropsychopharmacology. Neuropsychipharmacology 22, 108-124. doi: 10.1016/S0893-133X(99)00129-3

Miyazaki, T., Takase, K., Nakajima, W., Tada, H., Ohya, D., Sano, A., et al. (2012). Disrupted cortical function underlies behavior dysfunction due to social isolation. J. Clin. Invest. 122, 2690-2701. doi: 10.1172/JCI63060

Moghaddam, B. (1993). Stress preferentially increases extraneuronal levels of excitatory amino acids in the prefrontal cortex: comparison to hippocampus and basal ganglia. J. Neurochem. 60, 1650-1657. doi: 10.1111/j.14714159.1993.tb13387.x 
Moghaddam, B., Bolinao, M. L., Stein-Behrens, B., and Sapolsky, R. (1994). Glucocorticoids mediate the stress-induced extracellular accumulation of glutamate. Brain Res. 655, 251-254. doi: 10.1016/0006-8993(94)91622-5

Monroy, E., Hernández-Torres, E., and Flores, G. (2010). Maternal separation disrupts dendritic morphology of neurons in prefrontal cortex, hippocampus, and nucleus accumbens in male rat offspring. J. Chem. Neuroanat. 126, 497-505. doi: 10.1016/j.jchemneu.2010.05.005

Mueller, S. C., Maheu, F. S., Dozier, M., Peloso, E., Mandell, D., Leibenluft, E., et al. (2010). Early-life stress is associated with impairment in cognitive control in adolescence: an fMRI study. Neuropsychologia 48, 3037-3044. doi: 10.1016/j.neuropsychologia.2010.06.013

Musazzi, L., Milanese, M., Farisello, P., Zappettini, S., Tardito, D., Barbiero, V. S., et al. (2010). Acute stress increases depolarization-evoked glutamate release in the rat prefrontal/frontal cortex: the dampening action of antidepressants. PLoS ONE 5:e8566. doi: 10.1371/journal.pone.0008566

Nair, A., Vadodaria, K. C., Banerjee, S. B., Benekareddy, M., Dias, B. G., Duman, R. S., et al. (2007). Stressor-specific regulation of distinct brainderived neurotrophic factor transcripts and cyclic AMP response elementbinding protein expression in the postnatal and adult rat hippocampus. Neuropsychopharmacology 32, 1504-1519. doi: 10.1038/sj.npp.1301276

Nelson, C. A., Zeanah, C. H., Fox, N. A., Marshall, P. J., Smyke, A. T., and Guthrie, D. (2007). Cognitive recovery in socially deprived young children: the Bucharest Early Intervention Project. Science 318, 1937-1940. doi: 10.1126/science. 1143921

Nishi, M., Horii-Hayashi, N., and Sasagawa, T. (2014). Effects of early life adverse experiences on the brain: implications from maternal separation models in rodents. Front. Neurosci. 8:166. doi: 10.3389/fnins.2014.00166

Oomen, C. A., Soeters, H., Audureau, N., Vermunt, L., van Hasselt, F. N., Manders, E. M., et al. (2010). Severe early life stress hampers spatial learning and neurogenesis, but improves hippocampal synaptic plasticity and emotional learning under high-stress conditions in adulthood. J. Neurosci. 30, 6635-6645. doi: 10.1523/JNEUROSCI.0247-10.2010

Ovtscharoff, W. Jr., and Braun, K. (2001). Maternal separation and social isolation modulate the postnatal development of synaptic composition in the infralimbic cortex of Octodon degus. Neuroscience 104, 33-40. doi: 10.1016/S03064522(01)00059-8

Parfitt, D. B., Levin, J. K., Saltstein, K. P., Klayman, A. S., Greer, L. M., and Helmreich, D. L. (2004). Differential early rearing environments can accentuate or attenuate the responses to stress in male C57BL/6 mice. Brain Res. 1016, 111-118. doi: 10.1016/j.brainres.2004.04.077

Pawlak, R., Rao, B. S., Melchore, J. P., Chattarji, S., McEwen, B., and Strickland, S. (2005). Tissue plasminogen activator, and plasminogen mediate stress-induced decline of neuronal and cognitive functions in the mouse hippocampus. Proc. Natl. Acad. Sci. U.S.A. 102, 18201-18206. doi: 10.1073/pnas.0509232102

Pesonen, A., Eriksson, J. G., Heinonen, K., Kajantie, E., Tuovinen, S., Alastalo, H., et al. (2013). Cognitive ability and decline after early life stress exposure. Neurobiol. Aging 34, 1674-1679. doi: 10.1016/j.neurobiolaging.2012. 12.012

Popoli, M., Yan, Z., McEwen, B. S., and Sanacora, G. (2011). The stressed synapse: the impact of stress and glucocorticoids on glutamate transmission. Nat. Rev. Neurosci. 13, 22-37. doi: 10.1038/nrn3138

Reznikov, L. R., Grillo, C. A., Piroli, G. G., Pasumarthi, R. K., Reagan, L. P., and Fadel, J. (2007). Acute stress-mediated increases in extracellular glutamate levels in the rat amygdala: differential effects of antidepressant treatment. Eur. J. Neurosci. 25, 3109-3114. doi: 10.1111/j.1460-9568.2007. 05560.x

Romeo, R. D., and McEwen, B. S. (2006). Stress and the adolescent brain. Ann. N. Y. Acad. Sci. 1094, 202-214. doi: 10.1196/annals.1376.022

Sanacora, G., Treccani, G., and Popoli, M. (2012). Towards a glutamate hypothesis of depression: an emerging frontier of neuropsychopharmacology for mood disorders. Neuropharmacology 62, 63-77. doi: 10.1016/j.neuropharm.2011.07.036

Shair, H. N. (2007). Acquisition and expression of a socially mediated separation response. Behav. Brain Res. 182, 180-192. doi: 10.1016/j.bbr.2007. 02.016

Slotten, H. A., Kalinichev, M., Hagan, J. J., Marsden, C. A., and Fone, K. C. (2006). Long-lasting changes in behavioural and neuroendocrine indices in the rat following neonatal maternal separation: gender-dependent effects. Brain Res. 1097, 123-132. doi: 10.1016/j.brainres.2006.04.066
Sousa, V. C., Vital, J., Costenla, A. R., Batalha, V. L., Sebastião, A. M., Ribeiro, J. A., et al. (2014). Maternal separation impairs long term-potentiation in CA1-CA3 synapses and hippocampal-dependent memory in old rats. Neurobiol. Aging 35, 1680-1685. doi: 10.1016/j.neurobiolaging.2014.01.024

Suri, D., Veenit, V., Sarkar, A., Thiagarajan, D., Kumar, A., Nestler, E. J., et al. (2013). Early stress evokes age-dependent biphasic changes in hippocampal neurogenesis, BDNF expression, and cognition. Biol. Psychiatry 73, 6586-6666. doi: 10.1016/j.biopsych.2012.10.023

Takatsuru, Y., Eto, K., Kaneko, R., Masuda, H., Shimokawa, N., Koibuchi, N., et al. (2013). Critical role of the astrocyte for functional remodeling in contralateral hemisphere of somatosensory cortex after stroke. J. Neurosci. 33, 4683-4692. doi: 10.1523/JNEUROSCI.2657-12.2013

Takatsuru, Y., Ishikawa, T., Kohsaka, S., Nabekura, J., and Koibuchi, N. (2015). Early-life stress increases the motility of microglia in adulthood. J. Physiol. Sci. 65, 187-194. doi: 10.1007/s12576-015-0361-Z

Takatsuru, Y., Yoshitomo, M., Nemoto, T., Eto, K., and Nabekura, J. (2009a). Maternal separation decreases the stability of mushroom spines in adult mice somatosensory cortex. Brain Res. 1294, 45-51. doi: 10.1016/j.brainres.2009.07.092

Takatsuru, Y., Fukumoto, D., Yoshitomo, M., Nemoto, T., Tsukada, H., and Nabekura, J. (2009b). Neuronal circuit remodeling in the contralateral cortical hemisphere during functional recovery from cerebral infarction. J. Neurosci. 29, 10081-10086. doi: 10.1523/JNEUROSCI.163809.2009

Takayasu, Y., Iino, M., Takatsuru, Y., Tanaka, K., and Ozawa, S. (2009). Functions of glutamate transporters in cerebellar Purkinje cell synapses. Acta Physiol. (Oxf.) 197, 1-12. doi: 10.1111/j.1748-1716.2009.02019.x

Tinazzi, M., Marotta, A., Fasano, A., Bove, F., Bentivoglio, A. R., Squintani, G., et al. (2013). Aristotle's illusion reveals interdigit functional somatosensory alterations in focal hand dystonia. Brain 136, 782-789. doi: 10.1093/brain/aws372

Toya, S., Takatsuru, Y., Amano, I., and Koibuchi, N. (2013). The molecular mechanism of early life stress for synaptic instability in somatosensory cortex. J. Physiol. Sci. 63:S152.

Toya, S., Takatsuru, Y., Kokubo, M., Amano, I., Shimokawa, N., and Koibuchi, N. (2014). Early-life-stress affects the homeostasis of glutamatergic synapses. Eur. J. Neurosci. 40, 3627-3634. doi: 10.1111/ejn.12728

Trachtenberg, J. T., Chen, B. E., Knott, G. W., Feng, G., Sanes, J. R., Welker, E., et al. (2002). Long-term in vivo imaging of experience-dependent synaptic plasticity in adult cortex. Nature 420, 788-794. doi: 10.1038/ nature 01273

Tremblay, M. E. (2011). The role of microglia at synapses in the healthy CNS: novel insights from recent imaging studies. Neuron Glia Biol. 7, 67-76. doi: 10.1017/S1740925X12000038

Vyas, A., Mitra, R., Shankaranarayana Rao, B. S., and Chattarji, S. (2002). Chronic stress induces contrasting patterns of dendritic remodeling in hippocampal and amygdaloid neurons. J. Neurosci. 22, 6810-6818.

Wake, H., Moorhouse, A. J., Miyamoto, A., and Nabekura, J. (2013). Microglia: actively surveying and shaping neuronal circuit structure and function. Trends Neurosci. 36, 209-217. doi: 10.1016/j.tins.2012.11.007

Wigger, A., and Neumann, I. D. (1999). Periodic maternal deprivation induces gender-dependent alterations in behavioral and neuroendocrine responses to emotional stress in adult rats. Physiol. Behav. 66, 293-302. doi: 10.1016/S00319384(98)00300-X

Yuen, E. Y., Liu, W., Karatsoreos, I. N., Feng, J., McEwen, B. S., and Yan, Z. (2009). Acute stress enhances glutamatergic transmission in prefrontal cortex and facilitates working memory. Proc. Natl. Acad. Sci. U.S.A. 106, 14075-14079. doi: 10.1073/pnas.0906791106

Conflict of Interest Statement: The authors declare that the research was conducted in the absence of any commercial or financial relationships that could be construed as a potential conflict of interest.

Copyright (c) 2015 Takatsuru and Koibuchi. This is an open-access article distributed under the terms of the Creative Commons Attribution License (CC BY). The use, distribution or reproduction in other forums is permitted, provided the original author(s) or licensor are credited and that the original publication in this journal is cited, in accordance with accepted academic practice. No use, distribution or reproduction is permitted which does not comply with these terms. 